\title{
PAVEMENT MANAGEMENT: A SERVICE-BASED OPTIMAL ALLOCATION OF ROADS' INTERVENTIONS
}

\author{
LUIS AMADOR-JIMENEZ ${ }^{1} \&$ LEONARDO SERRANO $^{2}$ \\ ${ }^{1}$ Department of Building, Civil and Environmental Engineering, Concordia University, Canada. \\ ${ }^{2}$ Government of El Oro, Ecuador.
}

\begin{abstract}
This paper presents a novel method to use accessibility of the population to basic services of health and education on a service-based optimization of road maintenance and rehabilitation. The methodology expands typical performance-based decision making by considering the total travel time that users in rural locations spend to commute to a hospital or a university. The method reallocates investments in order to minimize levels of surface roughness and total travel time. Travel time considers expected speed from the combination of a set of elements such as type of terrain and pavement surface and its condition. A case study of about $960 \mathrm{~km}$ of strategic roads in the province of El Oro in Ecuador was used to demonstrate the application of the method. It was found that a massive campaign of paving should be undertaken in order to both improve average road conditions and the accessibility to basic services. The system dedicated about half of the budget to convert gravel roads into paved ones and the other half for maintenance and rehabilitation of the existing network. It was also found that a minimum budget (US\$6,000,000) to achieve good results from a mere condition perspective was not enough and that an extra $33 \%$ financial resources were required to achieve the accessibility goals of reducing aggregated strategic-network travel time. Future research should consider the ability to realign a road within the decision-making system as well as the adaptation of this approach to urban areas with intersections experiencing congestion.
\end{abstract}

Keywords: condition, interventions, management, pavements, travel time.

\section{INTRODUCTION}

Road management systems (RMS) allow authorities to allocate resources towards up keeping roads in good condition to support the movement of people and freight. However, it is rare to find a management system that considers direct user's needs or its economic contribution [1-3].The Ecuadorian province of El Oro does not count with an RMS, therefore being unable to take effective decisions to maintain and upgrade their roads in order to improve the quality of life of the people, especially those located in rural zones [4]. A road in good condition (especially in rural settings) guarantees better accessibility to markets, schools and healthcare, connecting people with jobs and increasing their opportunities of employment, thereby playing an important role in the mitigation of poverty and improving the quality of life of the inhabitants [5-7]; of course, the adequate economic environment for jobs creation and of skills of the human capital are required in the mix.

Roads in poor condition, as well as inadequate alignments and deteriorated pavements not only prevent prompt access to basic services of health and education but also damage agricultural goods because travel time increases, which impact the costs of transportation and subsequently affect the costs of every commodity typically exported to international markets (the same applies for those goods being imported from abroad towards local markets) [8].

This paper proposes the use of an accessibility indicator based on travel time of peoples commute to hospitals and school [5]. A case study of the province of El Oro is used to illustrate the approach. The proposed indicator measures total impedance for those inhabitants 
requiring commuting on a regular basis towards hospitals and universities [9]. The indicator considers the type of road surface, its condition and geometric alignment [7], in order to take decisions aiming to minimize total travel time of the population [8] and maximize overall surface condition.

\section{LITERATURE REVIEW}

\subsection{Accessibility}

The concept of accessibility first appeared in the 1950s [9]. At that time, there was a consensus towards the need to improve the social context in developing countries. Health was recognized as the most important factor to achieve this goal [1] and accessibility was defined in terms of proximity to basic services. This concept was understood as a problem of the supply of services and the ease to reach them and from this optic it was required to eliminate any physical barriers such as adverse geographic features, or man-made barriers [6]. Other elements of accessibility were related to economic barriers to access health services given the income limitations and public medical coverage [5, 7].

Accessibility can be thought of as a measure of built environmental changes happening from an urban planning and land use perspective. Two elements could be identified: first, the location to which people want to commute and second, the effort required to get there. Accessibility is an instrument of basic analysis for transportation infrastructure and a link between land use and transportation infrastructure [5, 6]. In this paper the transportation systems collapses to the road network and the main concern to improve spatial accessibility of human activities (basic services, leisure, employment and production) have been reviewed [3]. An extended approach will consider other modes of transportation within an urban region, in an accessible city where its inhabitants can move easily through the streets, with independence; we leave this for future research. For this research, accessibility is defined as the impedance associated to travel time that is required to commute towards basic services of health and education by those users requiring such services [10].

\subsection{Road management systems}

An RMS allocates resources (what to do, when and how) in order to reach and sustain adequate levels of service (classically thought off as condition) for the preservation of a road network. It includes the planning and execution of interventions (i.e. preservation, maintenance, rehabilitation) for the upkeep or upgradation of the network to better support economic and social activities $[11,12]$. In some cases, an RMS involves changes in the organization to better align the organization's processes with the decision support tools and the long-, medium- and short-term plans and their implementation. A management model is a systematic and rational way of undertaking decisions for an organization; that is, the sequence in which decisions should be organized and resolved [13].

A management system is typically connected to a geographical information system (GIS), which serves as an interphase to display in graphical form (maps) all data associated to the road network. This enables the spatial location of features and any other related information [12]. 


\subsection{Classical mathematical formulation for performance-based optimization}

The mathematical formulation used in this paper corresponds to an extension of that found in [14-16]. The decision-making attempts to find the minimum level of total network roughness (Eqn (1)), scheduling intervention $(j)$ on segments $(i)$ during time $(t)$. The constraints created total cost (Eqn (2)) from unitary cost of treatment $j$ on asset $i$ during year $t\left(c_{t i j}\right)$ times the road segment's length $\left(L_{i}\right)$ times the decision variable (which is one when treatment $j$ is applied) and restricted it to the annual budget $\left(B_{t}\right)$ for each year of the analysis period. For each period, a transfer function for roughness $R_{t, i}$ (Eqn (1)) translates the previous year's roughness condition $\left(R_{t-1, i}\right)$ into the current year's condition $\left(R_{t, i}\right)$ following two possible outcomes for the binary decision variable and the drop in roughness associated to improvement $(I)$ or the increase in roughness due to deterioration $(D)$ for the current level of condition as given by performance models and treatment effectiveness. This produces chains of possible decisions (also called enumeration process (14)) from which the optimization selects the optimum path. The optimal path reflects a set of variables $x_{i, t, j}$ that represent the allocation of interventions to segments during selected periods of time. This results in the most cost-effective manner to invest annual resources to achieve the highest possible value of road conditions.

$$
\begin{gathered}
\text { MAXIMIZE Z }=\sum_{t=1}^{T} \sum_{i=1}^{N} L_{i} R_{t, i} \\
R_{t, i}=\left(x_{t, i}\right)\left(R_{t-1, i}-I\right)+\left(1-x_{t, i}\right)\left(R_{t-1, i}+D\right) \\
\text { Subject to: } \sum_{i=1}^{\mathrm{N}} \sum_{j=1}^{J} C_{t, j} x_{i, t, j} L_{i} \leq B_{t} \text { for each year } t
\end{gathered}
$$

\section{METHODOLOGY}

This paper suggests the use of an indicator of accessibility based upon total travel time for people commuting to basic services and is estimated as a cumulative value of total travel demand for each road segment (Fig. 1). The indicator uses average expected speed (in meters per second) which depends on the surface material, geometric alignment (through type of terrain as a proxy) and the current level of condition. In this manner, travel time on an asphalt road is lesser than that of an unpaved road, similarly a road in poor condition or with a complex alignment exhibits larger travel time.

Surface condition was directly linked to road's roughness [17]. Travel distance was defined in meters and obtained from a geo-referenced map of roads provided by the Provincial Government of El Oro [4]. The map was processed to generate routes and each route was subdivided into segments of $100 \mathrm{~m}$ (except the final segment of each route that was allocated the remaining length). Accumulated values of population travelling towards a hospital (or university) multiplied by travel time (based on the abovementioned characteristics) were assigned to each road segment (Fig. 1).

\subsection{Extended formulation to incorporate accessibility}

The classical mathematical formulation presented before [14] was extended to incorporate an indicator of total travel time that depended on surface condition (roughness index) and type 


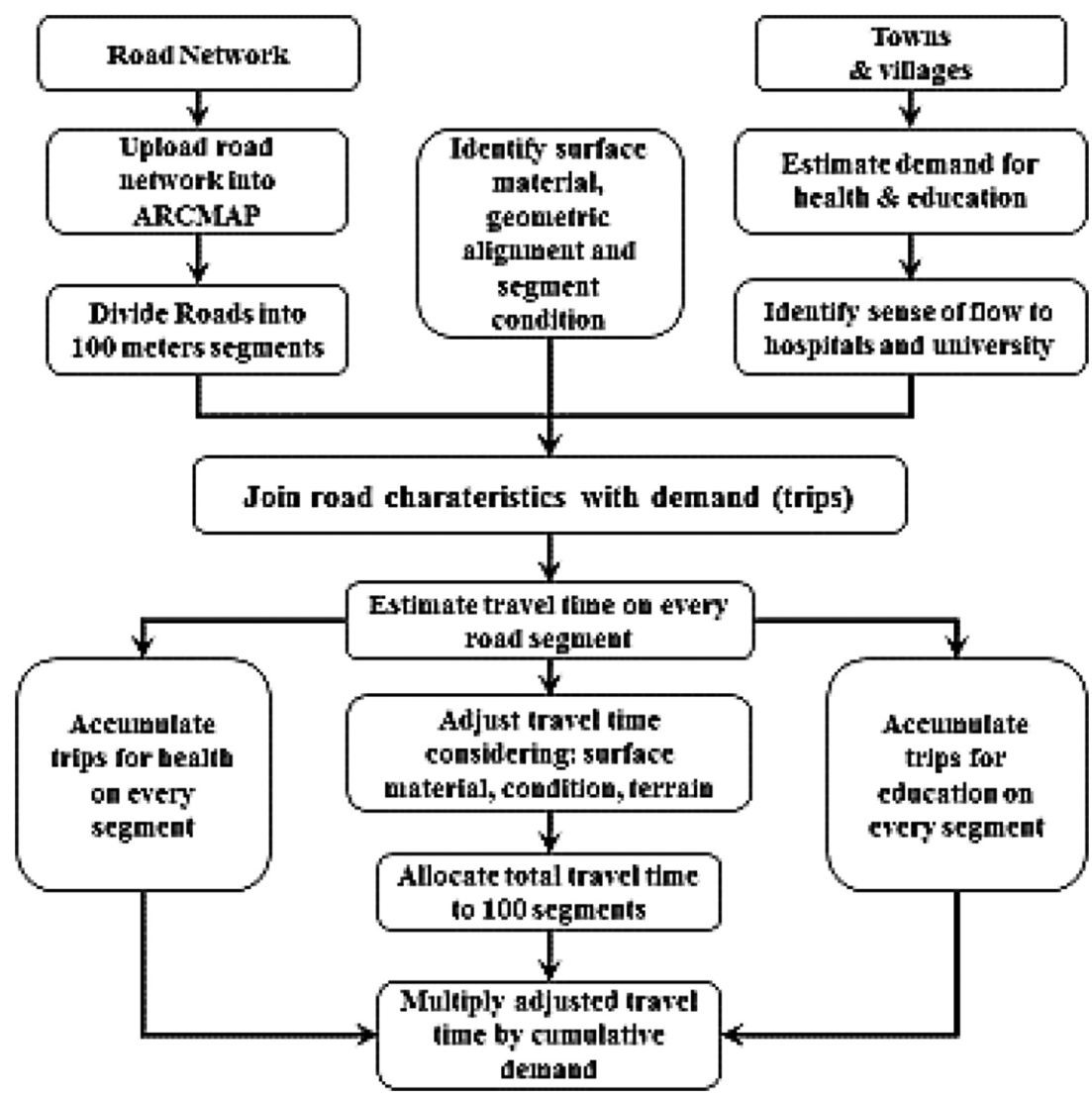

Figure 1: Methodology to include travel time and demand into the new objective function.

of surface (alignment was not incorporated). The objective was to minimize total travel time $(Z)$, which consisted of the travel time $(T)$, multiplied for the demand in number of users $(P)$ and the roughness value $(R)$ as shown on eqn (3), other constraints remained the same (Eqn (4)). Future research could expand this indicator by considering the benefits of horizontal/vertical realignment and of capital projects that made use of tunnels [5]. It is suggested that practical applications use a 4-step model with discrete choice methods to estimate travel demand $(\mathrm{P})$.

$$
\begin{gathered}
\text { MINIMIZE Z }=\sum_{t=1}^{T} \sum_{i=1}^{N}\left(R_{t, i}\right)\left(T_{t, i}\right)\left(P_{i}\right)+\sum_{t=1}^{T} \sum_{i=1}^{N} L_{i} R_{t, i} \\
\text { Subject to: } \sum_{i=1}^{\mathrm{N}} \sum_{j=1}^{J} C_{t, j} x_{i, t, j} L_{i} \leq B_{t} \text { for all } t
\end{gathered}
$$

The new objective encompasses roughness condition $\left(\mathrm{R}_{\mathrm{ti}}\right)$, total demand $\left(\mathrm{P}_{\mathrm{i}}\right)$ and travel time $\left(\mathrm{T}_{\mathrm{ti}}\right)$; hence, these three elements will guide the selection of the most cost-effective interventions capable of reducing roughness, or travel time, demand in terms of population remains constant in this analysis. Travel time over intervened roads reduces as a consequence of the improvement of the road surface condition. 


\section{CASE STUDY: PROVINCE OF EL ORO, ECUADOR}

The province of $E l$ Oro is a coastal region with $5.7 \mathrm{~km}^{2}$ of flat and mountainous lands at the south of Ecuador at the limit with Peru, it counts with about 600,000 inhabitants at 9 major urban areas and about 212 small towns and villages. It exports bananas, shrimp, cocoa and gold (4). The provincial road network consists of $3037 \mathrm{~km}$, of which $390 \mathrm{~km}$ are state highways and $2647 \mathrm{~km}$ are provincial roads. State highways are classified into $212 \mathrm{~km}$ of arterial corridors and $178 \mathrm{~km}$ of collectors [4].

\subsection{Travel time}

The travel times were based on averaged speed depending on the type of surface, its condition and the type of terrain as a proxy of the impedance role of geometric alignment (mountainous, flat or undulated). Levels of congestion at intersections was based on the analysis given the rural nature of this province, and future research must look into it.

Tables 1 and 2 contain speeds and travel times for segments in fair conditions (roughness index of one), those values can be multiplied by the roughness index in order to determine the speed and travel times corresponding to segments in other levels of deterioration. This implies that fair condition is the basis with a value of one. Table 2 shows travel time in seconds for segments of 100 meters.

\subsection{Travel demand to health and university education}

Accessibility was based on an estimation of demand for health or education services that considered individuals located in 212 towns in 12 regions of the province, individuals were categorized in ages associated with higher levels of demand for such services. People between the ages of 19 and 45 years were used to estimate demand to university education (as it is free

Table 1: Estimated average speed (fair condition) in kph.

\begin{tabular}{lccc}
\hline Surface/Geometry & Flat & Mountainous & Undulated \\
\hline Concrete & $90-100$ & $50-60$ & $60-70$ \\
Asphalt & $90-100$ & $50-60$ & $60-70$ \\
Gravel & $60-70$ & $30-40$ & $40-50$ \\
Dirt & $50-60$ & $20-30$ & $30-40$ \\
\hline
\end{tabular}

Table 2: Travel time in seconds for $100 \mathrm{~m}$ segment in fair condition.

\begin{tabular}{lccc}
\hline Geometry/Surface & Flat & Mountainous & Undulated \\
\hline Concrete & 3.79 & 6.55 & 5.54 \\
Asphalt & 3.79 & 6.55 & 5.54 \\
Gravel & 6.55 & 12.00 & 9.00 \\
Dirt & 7.20 & 14.40 & 10.29 \\
\hline
\end{tabular}


Table 3: Aggregated demand of daily trips for health and education motives.

\begin{tabular}{lcc}
\hline Regions & Health demand & Education demand \\
\hline Atahualpa & 400 & 1737 \\
Arenillas & 296 & 2298 \\
Balsas & 112 & 813 \\
El Guabo & 719 & 7833 \\
Las Lajas & 119 & 837 \\
Machala & 179 & 1779 \\
Marcabelí & 20 & 100 \\
Pasaje & 1201 & 8959 \\
Piñas & 689 & 3531 \\
Portovelo & 167 & 989 \\
Santa Rosa & 74 & 580 \\
\hline
\end{tabular}

in Ecuador) and those over 60 years were used to estimate demand to healthcare (Table 3). Our approach followed a basic gravitational method because the main purpose of the paper is focussed on developing a modified optimization framework and as such the travel demand is considered secondary. Practical applications should consider the use of more refined demand estimations such as those obtained by the use of discrete choice methods, cellular automata or any other agent-based disaggregated approach (18). Table 3 shows daily trips estimated for each commute motive and allocated in a cumulative fashion on the road network.

\subsection{Accessibility}

There are 185 health facilities in the province of El Oro (private clinics, hospitals, public clinics and health centers). Private clinics and health centrer were removed from the analysis because most locals do not have the financial means to pay for private services and health centres offer very limited services. Public clinics and hospitals (eight in total) were considered in the model and service areas for 15, 30, 45, 60 and 90 minutes estimated (Fig. 2). This paper considers free university education and presumes that about $50 \%$ of the individuals between the ages of 19 and 46 years will attend postgraduate school (there were no schooling statistics available for the province), only one university is available for the entire province (Fig. 2). About half of the province is located in rolling or mountainous terrain, which impacts travel time and overall accessibility.

\section{RESULTS AND DISCUSSION}

Commercial software REMSOFT (19) was used to support decision making by optimizing condition and travel time following two base scenarios: one with US\$6,000,000 and another one with US $\$ 8,000.000$ dollars per year for a 15-year planning period. Roads were classified in ranges of condition (Table 4) and interventions to improve them applied (16) following an operational window defined per range of condition.

Figure 3 and 4 shows the progression of roughness for asphalt and gravel roads for both base scenarios. As seen, gravel roads remain in better condition with a lower budget, such 

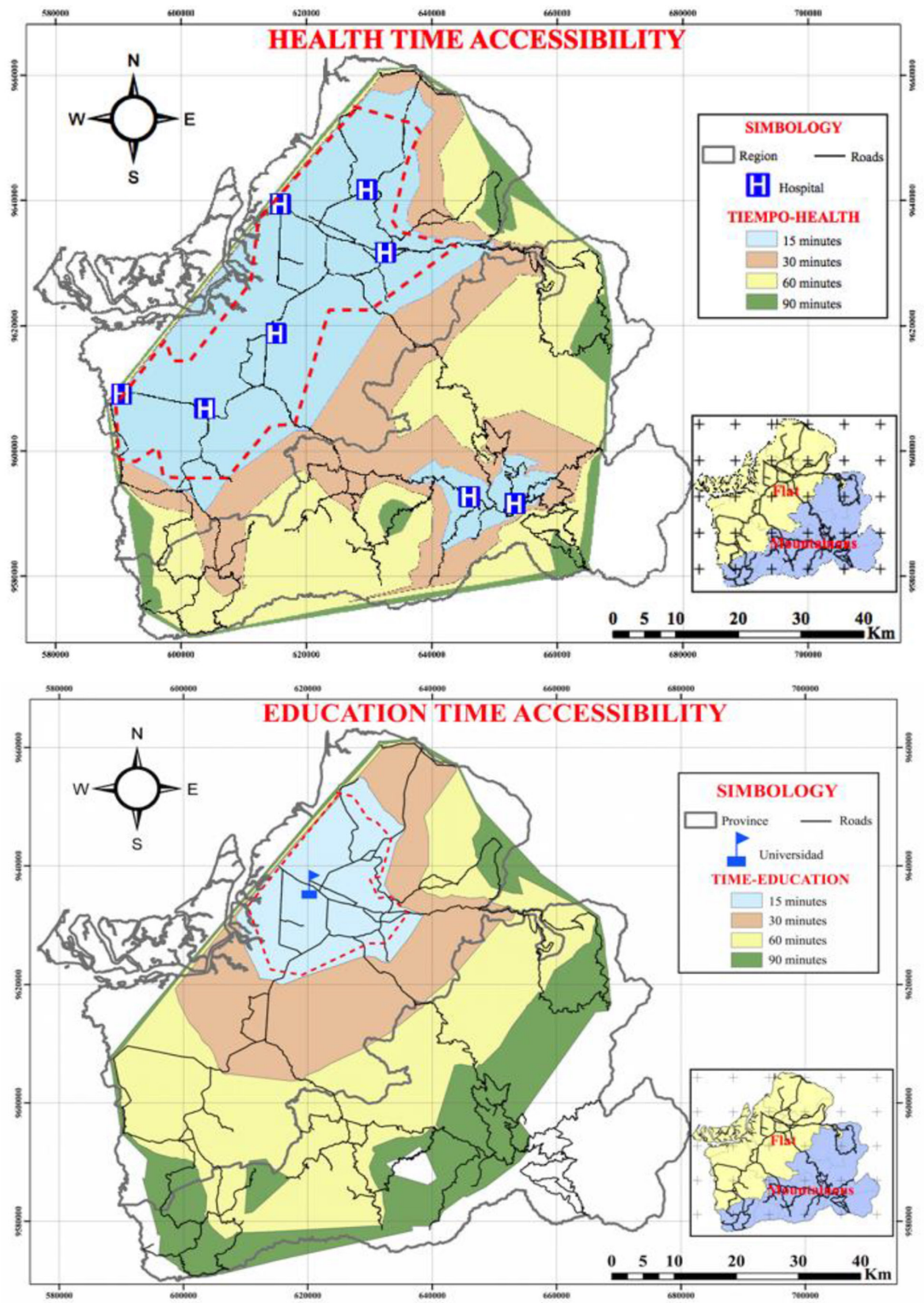

Figure 2: Current and future accessibility to Hospitals and University.

contradictory result could be explained by the fact that the decision-making support tool is dedicating more resources to asphalt roads (regardless of budget level) and to the conversion of gravel roads into asphalt roads. In addition, it can be seen that in the short- and mediumterm a large amount of resources result in paved roads in better condition; however, after eight years both scenarios reach similar levels of mean network condition. For this reason a budget of US\$6,000.000 seems enough under these circumstances. 
Table 4: Operational Windows.

\begin{tabular}{lccc}
\hline Intervention & Gravel & Asphalt & Cost $^{+}(\$ / \mathrm{m})$ \\
\hline Crack Sealing & & $0-1.8$ & 6 \\
Microsurfacing & & $1.8-2.7$ & $50^{*}$ \\
Resurfacing & & $2.7-10$ & $50^{*}$ \\
Reconstruction & & 10 and more & 200 \\
Conversion to Asphalt & 5 or less & & 350 \\
Recompaction & 10 to 25 & & 11 \\
Grading + Compaction & $25+$ & & 22 \\
\hline
\end{tabular}

Notes: ${ }^{+}$Costs based on government estimates. ${ }^{*}$ No distinction made

\subsection{Scenario with accessibility}

An accessibility scenario was initially constrained by a budget of US $\$ 6,000.000$; however, the obtained results revealed the decay of both networks (gravel and asphalt), for this reason, the budget was increased again to US $\$ 8,000,000$ which resulted in sustained good condition for asphalt roads and long run convergence of gravel to good levels as shown in Figure 3.

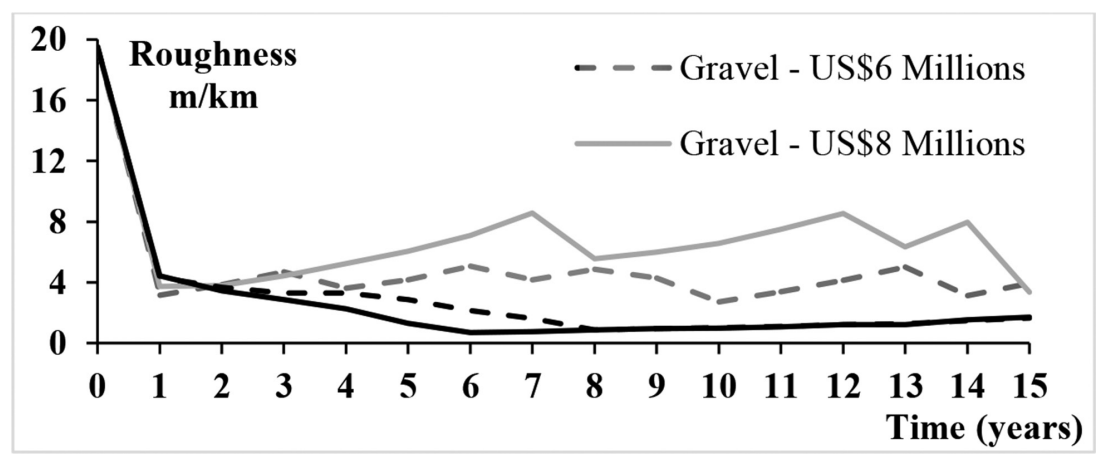

Figure 3: Average progression of roughness in $\mathrm{m} / \mathrm{km}$ across time.

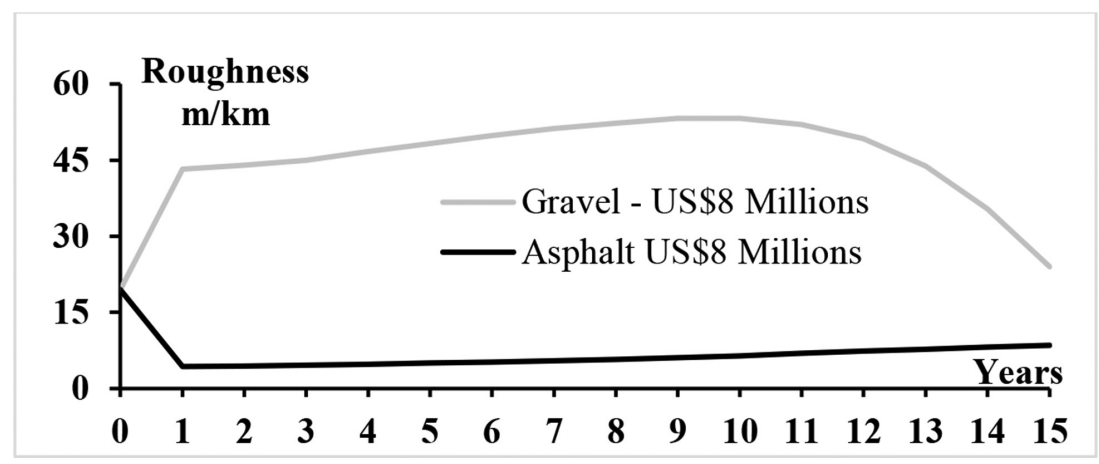

Figure 4: Mean progression of roughness in $\mathrm{m} / \mathrm{km}$ for the accessibility scenario. 


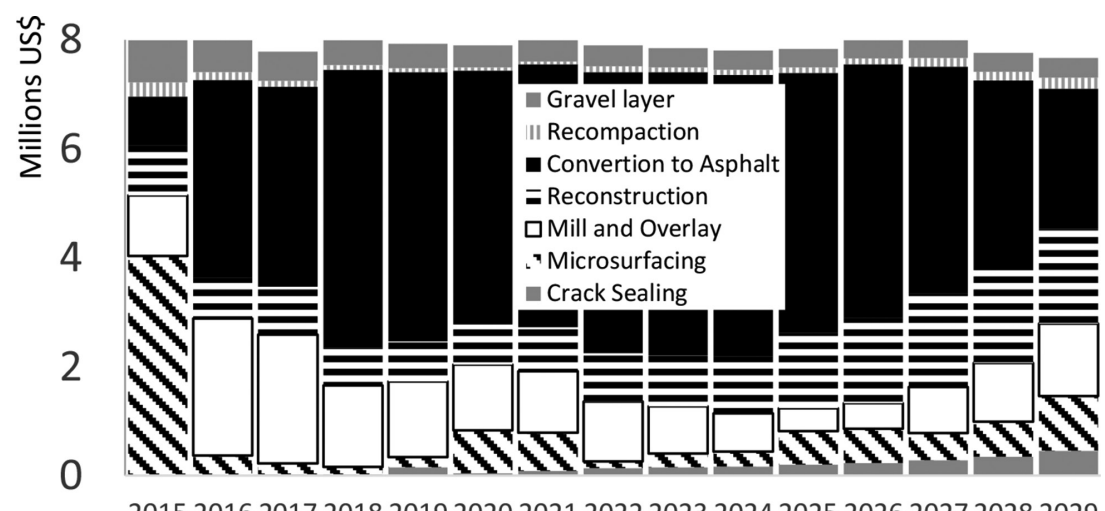

Figure 5: Annual investments per type of intervention (US\$).

Distribution of resources per type of treatment is illustrated in Figure 5. The great majority of financial resources was intended for conversion of gravel roads into asphalt. In a lesser proportion, resources are spent for mill and overlay, microsurfacing and reconstruction. During the first period, one can observe an exceptional campaign of microsurfacing attempting to prevent the decay of roads at a good level of condition.

Results from the allocation of interventions including the conversion of gravel roads to paved asphalts impacted the travel time and overall accessibility of the health and education users as illustrated in Fig. 2.

\section{CONCLUSIONS AND FUTURE RESEARCH}

This paper demonstrates the incorporation of travel time from remotely located towns to reach basic services of education and health services, with the goal to allocate treatments to those roads that serve a higher demand and with higher levels of surface deficiencies.

It was found that a budget of US\$6 million was required to keep the road network at an acceptable level of surface condition. However, after incorporating travel time, it was found that such an amount was not enough and that at least US\$8 million was required to return to an acceptable level of surface in the long run for both gravel and asphalt roads. It was found that a better strategy is to focus the majority of the economic resources during the first year on microsurfacing, with the aim of keeping good pavements in good condition, and to concentrate resources from the second year on for conversion of gravel roads into asphalt roads. At a secondary level, annual investments were directed to maintenance and rehabilitation activities to sustain good roads and to recover those in bad condition. By the end of a 15-year period, the majority of roads are expected to be paved. Road realignment and measures to counteract congestion should be added into this methodology in future research. Even though this case study is particular to regions in developing nations, its framework is applicable anywhere, as such accessibility is applicable to freight when considering travel time towards ports and markets, or for workers in any urban area when looking at their travel time during peak hour commute; as such, interventions could include retrofitting of intersections to reduce congestion and improve travel time. 


\section{REFERENCES}

[1] Plessis-Fraissard, M., Planning roads for rural communities. transportation research record No. 1989. Transportation Research Board of the National Academies, Washington, D.C. 2007, pp. 1-8, 2007.

[2] Targa, F., Clifton, K.J. \& Mahmassani, H.S., Economic activity and transportation access: An econometric analysis of business spatial patterns. Transportation Research Record No. 1932. Transportation Research Board of the National Academies, Washington, D.C. 2005, pp. 61-71, 2005.

[3] Santos, B., Antunes, A. \& Miller, E.J., Integrating equity objectives in a road network design model. Transportation Research Record No. 2089 Transportation Research Board of the National Academies, Washington, D.C. 2008, pp. 35-42, 2008.

[4] G.P.A.O. EL ORO PLAN VIAL PROVINCIAL 2003-2013. Gobierno Provincial Autónomo de El Oro. 2003.

[5] Zhao, F. \& Chung, S., Contributing factors of annual average daily traffic in a Florida country. Transportation Research Record No. 1769 Transportation Research Board of the National Academies, Washington, D.C. 1999, pp. 113-122, 1999.

[6] Khan, S. \& Levy, D., Linking economic development to highway improvements. Transportation Research Record. Transportation Research Board of the National Academies, Washington, D.C, pp. 106-113, 2003.

[7] Visser, A.T. \& Hall, S., Innovative and cost-effective solutions for roads in rural areas and difficult terrain. Transportation Research Record No.1919. Transportation Research Board of the National Academies, Washington, D.C, pp. 169-173, 2003.

[8] Merilainen, A., Impact of low-volume road network improvements on rural community development in finland. Transportation Research Record No. 1559. Transportation Research Board of the National Academies, Washington, D.C, pp. 100-110. 1996.

[9] Levinson, D. \& Krizek, K.J., Planning for Place and Plexus: Metropolitan Land Use and Transport, 1st edn., Routledge, 2008.

[10] Marcet, J.E., Altamira, A.L., Bustos, M.G., Cordo, O.V., Mancini, P.G., Fernández, O.M. \& Pereyra, M.O., Evaluating accessibility of high-altitude valleys: application to andean region of San Juan, Argentina. Transportation Research Record No. 1989 Transportation Research Board of the National Academies, Washington, D.C, pp. 2033, 2007.

[11] Haas, R. \& Hudson, W.R., Pavement Management Systems, New York: McGraw Hill, 1994.

[12] TAC. Pavement Design and Management Guide, Ottawa: Transportation Association of Canada (TAC), 1997.

[13] Hudson, W.R., Haas, R. \& Uddin, W., Infrastructure Management: Integrating Design, Construction, Maintenance, Rehabilitation and Renovation, McGraw-Hill, USA, 1997.

[14] Watanatada, T. et al. The Highway Design and Maintenance Standards Model - HDM III. Washington D.C.: Word Bank - John Hopkins University. 1987.

[15] Li, N. \& Hass, R., Reliability-based processing of markov chains for modeling pavement network deterioration. In Transportation Research Record No 1524, TRB, National Research Council, Washington, D.C pp. 203-213. 1996.

http://dx.doi.org/10.3141/1524-24 
[16] Imani, A.F. \& Amador, L., Towards a sustainable pavement management: incorporating environmental impacts of pavement treatments into a performance-based optimization. Transportation Research Record No 2366, pp. 13-21, 2013. http://dx.doi.org/10.3141/2366-02

[17] Sayers, M.W., On the calculation of international roughness index from longitudinal road profile. Transportation Research Record No. 1501, Washington, D.C, pp. 1-12, 1995. 